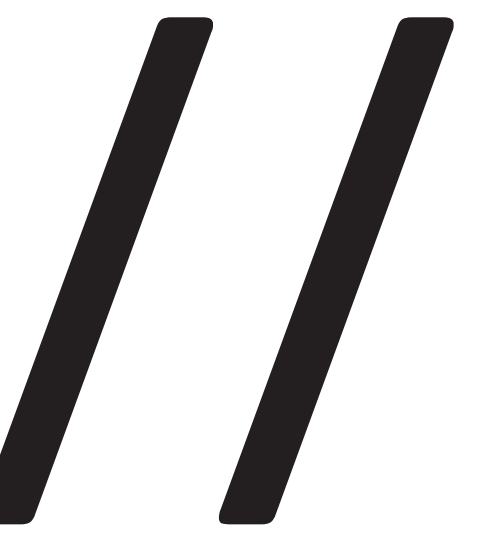

///////////////////

\title{
A imagem interessante: cinema e suspensão narrativa
}

The interesting image: cinema and narrative halt

\author{
João Vitor Resende Leal ${ }^{1}$
}


Resumo: este artigo busca investigar a partir de que momento, por quais critérios e com que exatidão podemos afirmar que há "suspensão narrativa", quais as qualidades das imagens que operam essa suspensão e quais as suas consequências na experiência do espectador. Para tanto, articularemos um panorama teórico sustentado por diversas noções - o "conceito estendido de moving-picture dance" (Carroll), a "fotogenia" (Epstein, Xavier), o "número musical" (Altman, Sutton), o "cinema de atrações" (Gaudreault, Borges), o "punctum" e o "terceiro sentido" (Barthes) e o "excesso" (Thompson) - e avançaremos que, ao rescindir com as motivações e com a lógica causal da trama, essa imagem "interessante por si própria" acaba por revelar uma "elasticidade" latente na própria narrativa cinematográfica. Palavras-chave: narrativa cinematográfica; suspensão narrativa; imagem cinematográfica; atração; elasticidade.

Abstract: this article intends to investigate when and in what way, by which criteria and how accurately can one affirm that there has been a "narrative halt", what are the qualities of the images that promote such halt and what are its consequences on the viewer's experience. For that matter, we will articulate several different notions - the "extended concept of moving-picture dance" (Carroll), "photogeny" (Epstein, Xavier), the "musical number" (Altman, Sutton), the "cinema of attractions" (Gaudreault, Borges), the "punctum" and the "third sense" (Barthes) and the "cinematic excess" (Thompson) - and we will suggest that, by rejecting the motivations and the causality of the plot, this image that is "interesting for its own sake" ultimately reveals a certain "elasticity" within cinema's narrative itself.

Key words: cinematographic narrative; narrative halt; cinematographic image; attraction; elasticity. 
Eu gosto do absurdo divino das imagens.

Manoel de Barros

\section{Zabriskie Point}

Ao final de Zabriskie Point (1970), de Michelangelo Antonioni, a jovem e idealista Daria (Daria Halprin) desce de seu carro para observar a explosão da casa de um inescrupuloso empresário, seu chefe e amante. Diversos planos em câmera lenta se sucedem, repetindo e prolongando o instante da detonação. Pedras, estilhaços de madeira, chamas e labaredas de fumaça preenchem a tela. Em seguida, na ausência de um esperado contraplano, de uma imagem de Daria a contemplar e reagir a essa enorme explosão, algo estranho se opera: a sequência parece adquirir textura e consistência tais que a descolam da narrativa. O filme continua a correr, cumprindo sua duração ao nos enviar novas imagens de explosões em câmera lenta, mas essas imagens não tracionam mais história alguma. O drama de Daria parece girar em falso, sem sair do lugar.

Nesse momento, o espectador talvez questione se aquilo que vê na tela é um delírio da personagem (hipótese reforçada pela trilha musical psicodélica) ou uma realidade dentro da diegese; talvez, conhecendo a temática da contracultura explorada pelo filme, ele busque atribuir um significado político às explosões. Mas esse mesmo espectador sabe, por uma espécie de intuição que o filme até então não lhe havia solicitado (com a notável exceção de uma cena de orgia em pleno deserto), que tais questões deixaram de ser pertinentes. Diante dos quase cinco minutos da atração plástico-musical constituída pelos estilhaços que dançam uma coreografia improvisada e única sob o céu azul ao som de Pink Floyd, pouco interessa interpretar ou acompanhar a trama. É certo, esses interesses retornarão antes que o filme termine; no momento, contudo, a narrativa e seus preceitos se encontram categoricamente suspensos ${ }^{2}$.

Descrevemos essa cena emblemática para assinalar o ponto de partida e estabelecer o horizonte do que pretendemos discutir neste artigo: a natureza daquilo que chamaremos aqui de suspensão narrativa. Nossa hipótese já está lançada: é sobretudo quando a narrativa se torna estéril que precisamos retornar à imagem (visual e sonora), sendo preciso buscar na imagem aquilo que tanto perturba, e de maneira

${ }^{2}$ Referimo-nos à narrativa convencional, que se estrutura em relações causais, tem começo e fim e evolui através das motivações de seus personagens em uma trama lógica que se desdobra em uma série de acontecimentos. Sobre a narrativa cinematográfica, ver BORDWELL, 1985 e GAUDREAULT; JOST, 2009. 
tão calculada, a narrativa. A imagem se torna foco de atenção sobretudo quando já não está plenamente a serviço de nenhuma história, de nenhum sentido. Interessa-nos, pois, investigar a partir de que momento, por quais critérios e com que exatidão podemos afirmar que há “suspensão narrativa”, quais as qualidades das imagens que operam essa suspensão e quais as suas consequências na experiência do espectador.

Para tanto, ofereceremos um panorama teórico que mobilizará diversas noções de autores que, direta ou indiretamente, se ocuparam da relação entre a imagem e a narrativa cinematográfica. Tais noções - o "conceito estendido de moving-picture dance", a "fotogenia”, o "número musical”, a "atração", o "punctum", o "terceiro sentido" e o "excesso" - serão tratadas como variações sobre um mesmo tema: cada variação se fará perceber nas demais, mas cada uma delas irá expor também um aspecto distinto, uma possibilidade distinta de abordagem ao tema principal que é a suspensão narrativa. Uma vez concluído o percurso, teremos testemunhado o interesse da imagem que, no suspender a narrativa, se revela plenamente capaz de modelá-la ou deformá-la, isto é, de evidenciar seu caráter "elástico". Assim, evitaremos encarcerar a reflexão e sugeriremos, como conclusão, ainda outro viés para o problema da suspensão narrativa, apontando não apenas para a potência da imagem, como terão então feito as noções teóricas privilegiadas aqui, mas também para uma plasticidade própria à narrativa cinematográfica.

\section{Movimentos dançantes}

Dissemos que, em Zabriskie Point, os estilhaços da explosão dançam. A analogia com a dança não é gratuita e nos servirá como ponto de partida. Em função da longa duração, da câmera lenta, da frontalidade dos planos, da ausência de contracampo, da trilha musical, enfim, dos diversos procedimentos de mise-en-scène que produzem a sequência, o movimento dos estilhaços não é totalmente justificado: não responde a nenhuma determinação específica da história, não tem nenhuma causa e nenhuma consequência, nem induz a nenhuma interpretação em particular. $\mathrm{O}$ movimento dos estilhaços se apresenta pleno e exuberante em si mesmo, o que Noël Carroll chamaria de um movimento interessante por si próprio, "for its own sake". Seria o suficiente para aceitá-lo como uma dança: "podemos descrever o movimento como dançante simplesmente porque a dança é a forma de arte especializada na exibição do movimento por si próprio" (CARROLL, 2001, p. 58).

Em seu artigo "Toward a definition of moving-picture dance" (2001), Carroll está preocupado em compreender as relações estabelecidas entre dança e cine- 
ma. Após desenvolver o "conceito central de moving-picture dance", que compreende diferentes formas de apresentação da dança através das imagens em movimento, ele propõe um conceito estendido que designa, justamente, qualquer movimento que seja "interessante por si próprio", independentemente daquilo que tradicionalmente reconhecemos como dança. É verdade que esse conceito estendido foi cunhado sob medida para dar conta de filmes de vanguarda ou experimentais que trabalham com imagens não figurativas e que todavia são tomados como dança, como o Ballet mécanique de Fernand Léger e Dudley Murphy (1924). No entanto, o próprio Carroll destaca sua pertinência para a análise de filmes narrativos convencionais, citando como exemplo os elaborados movimentos de kung-fu dos filmes de Bruce Lee: “além de ser interessante por seu conteúdo narrativo, a cine-coreografia marcial de Bruce Lee também é interessante por si própria” (CARROLL, 2001, p. 58). Assim, seu "conceito estendido de moving-picture dance" ecoa um conceito mais antigo e abrangente, o de fotogenia, tal como o defendeu a vanguarda francesa da década de 1920 e, em particular, o cineasta e teórico Jean Epstein: é fotogênico tudo aquilo - coisas, seres, ideias - “cujo valor moral é aumentado pela reprodução cinematográfica”, sendo que apenas os "aspectos móveis" das coisas podem, de fato, ter seus "valores morais" aumentados (EPSTEIN, 1974, p. 137-138). Dito de outra forma, para Epstein, a fotogenia "deve ser procurada no que é "móvel" (XAVIER, 1978, p. 99): é o movimento que está em destaque.

Conceito-chave de uma geração que buscou compreender e afirmar a especificidade de uma arte cinematográfica pura, a fotogenia é de difícil definição, uma ideia "fértil na prática artística, mas problemática quando assumida no nível da explicação teórica” (XAVIER, 1978, p. 101). Ainda assim, por sua relevância histórica, consideramos oportuno apontar aqui sua proximidade - não assumida por Carroll em seu artigo, é verdade - com o "conceito estendido de moving-picture dance". Deste, por sua vez, interessa-nos reter ao menos dois aspectos. Em primeiro lugar, temos formulada a possibilidade de uma imagem cujo movimento é "interessante por si próprio", que detém o olhar ou nos leva a refletir sobre seu próprio caráter movente independentemente da narrativa que o acolhe (CARROLL, 2001, p. 60). Em segundo lugar, temos que esse "interesse por si próprio" não necessariamente exclui outros interesses, outras funções: um golpe de Bruce Lee pode ter um apelo coreográfico singular sem, com isso, deixar de ferir seus inimigos. 


\section{O número musical}

Visto que o cinema musical é o que mais abertamente apresenta movimentos dançantes, e não apenas em sentido figurado, é nele que encontraremos, de imediato, ações e gestos cujas motivações parecem estar além (ou aquém) da narrativa convencional. O musical, explica Martin Sutton, é permeado por números musicais que contrastam fortemente com os preceitos habituais da narrativa. Eles perturbam a lógica da história contada por serem, à primeira vista, redundantes, inconsequentes - o que não necessariamente é um demérito do filme. Para Sutton, enquanto a narrativa exerce uma função regulatória, realista e convencional, os números musicais são momentos libertários de espetáculo e fantasia:

O musical é essencialmente um gênero que se preocupa com a imaginação romântica/rebelde e sua batalha diária com uma ordem social inibidora e "realista". Essa batalha se desenvolve a partir da tensão entre a trama realista e o número espetacular/fantástico. Todo o realismo narrativo herdado do romance do século XIX (a trama linear, o desenvolvimento cronológico, a curva regular das emoções) está por trás dessa tensão. O número funciona como uma interrupção narrativa, uma tangente fantástica que ao mesmo tempo frustra e liberta o espectador (SUTTON, 1981, p. 191).

Também preocupado com o cinema musical clássico hollywoodiano, Rick Altman atenua a proposição de Sutton. Para ele, trata-se menos de uma "batalha" entre o número e a narrativa convencional e mais de um novo tipo de estrutura, de uma "narrativa de duplo foco" que concilia os dois regimes. Por essa perspectiva, o número musical deixaria de ser algo que atravanca a narrativa convencional, uma vez que não estamos mais nos domínios da narrativa convencional; ele seria, antes, o revelador de uma série de oposições entre personagens: acompanhamos ora o homem, ora a mulher, conhecendo suas diferenças e antecipando o momento em que eles, apesar de tudo, ficarão juntos. É nesse jogo de relações que a "narrativa de duplo foco" se constrói e nela, portanto, os preceitos da narrativa convencional são meramente secundários:

Não podemos mais apontar para a trama convencional do musical, chamá-la de desajeitada e de episódica, e sairmos satisfeitos. (...) A trama, sabemos agora, tem, logo de entrada, pouca importância; as oposições desenvolvidas na forma aparentemente gratuita dos números de canto e dança, no entanto, são fundamentais no estabelecimento da estrutura e do sentido do filme (ALTMAN,1987, p. 27). 
Por mais que nosso objetivo não seja analisar o cinema musical, recorremos aqui ao número musical porque ele nos permite testemunhar uma significativa perturbação da narrativa. Além disso, por mais que estejamos sensíveis à argumentação de Altman (que de fato nos parece consistente no âmbito dos musicais hollywoodianos clássicos), é a proposição de Sutton que levaremos adiante: como tentaremos mostrar a seguir, a perturbação da narrativa provocada pelo número é francamente perceptível, uma vez fora do gênero musical ${ }^{3}$, como suspensão narrativa, como algo que trava "batalha" com a narrativa convencional na medida em que fragiliza sua lógica e demanda outra postura espectatorial.

Acreditamos que essa oposição entre duas lógicas e duas posturas espectatoriais não é outra senão a conhecida distinção entre um "cinema narrativo", que reconhecemos como convencional, diegético e clássico, e o "cinema de atrações" característico do primeiro cinema, que reconhecemos como espetacular e exibicionista, mais preocupado em interpelar (surpreender, maravilhar, chocar) o espectador do que em contar uma história. Como apontou Cristian Borges, os números do cinema musical funcionam, tanto quanto mirabolantes sequências de ação ou cenas pornográficas, como atrações espetaculares, "números = atrações":

Fatalmente, observamos aí um inegável parentesco entre os números musicais e as 'atrações' que, segundo André Gaudreault, são o 'princípio dominante' dos primórdios do cinema, 'em contradição com o princípio dominante do cinema institucional: a narração' [GAUDREAULT, 2011, p.51]. Por outro lado, diz ele, 'o cinema narrativo está repleto de atrações' (BORGES, 2014, p. 51-52).

Na medida em que revela certa permeabilidade entre o "cinema narrativo" e o "cinema de atrações", o número musical atualiza aquilo que André Gaudreault e Tom Gunning denominaram "cinema de integração narrativa”. O termo, originalmente cunhado para definir o período intermediário entre o "cinema de atrações mostrativas” e o cinema clássico/institucional dominado pela narração, aponta para um processo de narrativização: “Os elementos de expressão cinematográfica foram sendo mobilizados, em todos os níveis, para fins narrativos" (GAUDREAULT e GUNNING, 2006, p. 373) e o espectador foi, cada vez mais, levado a interpretar o discurso cinematográfico através da história narrada. (GAUDREAULT e GUNNING, 2006, p. 374) ${ }^{4}$. A “integração narrativa” seria, assim, um processo de acli-

\footnotetext{
${ }_{3}^{3}$ Sobre o gênero musical, recomendamos o livro organizado por Altman que compreende o artigo de Sutton aqui mencionado (ALTMAN, 1981).

${ }^{4}$ A divisão do primeiro cinema entre um "sistema de atrações mostrativas" (período que iria até cerca de
} 
matação das atrações (danças, acrobacias, vistas espetaculares, imagens assustadoras etc.) em um modelo narrativo comparável àquele do romance do século XIX, onde primam verossímeis relações de causa-efeito. Parece-nos que o número musical retoma de forma exemplar essa dinâmica ao impor, a um cinema profundamente fundado em convenções narrativas como é o gênero musical, um momento não totalmente narrativizado.

Agora, para apoiar a ideia de que o grande modo pelo qual as atrações vêm incrustar o cinema narrativo é o modo da suspensão narrativa, fazem-se necessários alguns exemplos. Dentre as inúmeras possibilidades que se oferecem - pois "o cinema narrativo está repleto de atrações” -, optamos por seguir com o número musical na condição de atração operadora de suspensão narrativa. Contudo, para ampliar o perímetro de nossa reflexão evitando sua sujeição a um só gênero cinematográfico, privilegiaremos filmes não musicais. Fiquemos então com três filmes narrativos não musicais, que consideramos razoavelmente distintos um do outro e que são todavia pontuados por números musicais: Mauvais sang (Sangue ruim, Leos Carax, 1986), Paranoid Park (Gus Van Sant, 2007) e Galileo (A vida de Galileu, Joseph Losey, 1975).

\section{Alguns exemplos}

A certa altura de Sangue ruim, o mágico Alex (Denis Lavant) se depara com a impossibilidade de levar adiante seu relacionamento com Anna (Juliette Binoche), amante do gangster que o recrutou para um assalto particularmente elaborado. Após uma noite em segredo com Anna, ele sintoniza no rádio uma canção romântica e acende um cigarro. Por cerca de um minuto, vemos Alex fumando na varanda. Quando o locutor anuncia a canção seguinte - Modern love, de David Bowie -, ele começa a se contorcer de dor. Na sequência que se segue, Alex corre por uma rua escura fazendo piruetas, dando socos no ar e no próprio corpo, ao ritmo da música de Bowie. Em conformidade com a performance corporal do ator, a velocidade do travelling que o acompanha, a cenografia da rua vazia marcada pela verticalidade arquitetônica das fachadas e os match cuts empregados na montagem promovem uma abstração temporal e espacial, uma síncope visual que não encontra ecos no res-

1908) e um "sistema de integração narrativa” (que iria de 1908 a 1914, abrindo espaço ao domínio pleno da narração) foi proposta por Gaudreault e Gunning no artigo "Le cinéma des premiers temps: un défi à l'histoire du cinéma?”, publicado originalmente em 1986. No mesmo ano, Gunning publicou também o influente "The cinema of attraction: early film, its spectator and the Avant-Garde", que tornou corrente o uso do termo "cinema de atrações". Ver STRAUVEN, 2006. 
tante do filme - até que, subitamente, a música para, Alex dá meia volta e a narrativa retoma seu curso.

Já em Paranoid Park, as imagens de manobras de skate (com trilha musical que inclui texturas eletrônicas e baladas de Elliot Smith) constituem números musicais que mesclam improviso - nos enquadramentos pouco usuais e tremidos da câmera na mão - e coreografia - na plasticidade do movimento dos corpos e da própria câmera. A trama acompanha a carta-confissão do adolescente Alex (Gabe Nevins), acidentalmente responsável pela morte de um guarda ferroviário nos trilhos de trem próximos a uma pista de skate clandestina. Mais de uma vez a câmera segue skatistas anônimos na pista, executando ela própria algumas manobras como passos de uma dança construída para a fruição espectador. No registro distinto de um super- 8 extremamente granulado (remetendo a um tom documental que reforça a ideia de improviso) e em câmera lenta (que, por sua vez, acentua a dimensão coreográfica dos movimentos), essas imagens parecem indiferentes ao drama de Alex, filmado em $35 \mathrm{~mm}$. A elas pouco importa que Alex tenha decidido ocultar o acidente da família, dos amigos e do detetive que o interroga na escola. São imagens que se afirmam, notavelmente pela qualidade do movimento e pelo grão da película, como momentos independentes da narrativa.

Os números musicais de Sangue ruim e Paranoid Park parecem ter, portanto, a mesma textura e consistência que a cena de explosão de Zabriskie Point, também ela um número musical. O que lá éramos tentados a compreender como expressão da destruição do sistema capitalista, aqui somos tentados a compreender como expressão de angústia por um amor impossível ou de desejo juvenil de liberdade e libertação. Nas três cenas, contudo, essas tentadoras interpretações são insuficientes para dar conta da exuberância e singularidade do que vemos na tela.

Por fim, em A vida de Galileu (filme inspirado na peça de Bertolt Brecht sobre a vida do renomado astrônomo renascentista), um trio de rapazes faz as vezes de coro grego, antecipando de forma cantada a progressão da história. O trio aparece diversas vezes ao longo do filme, ora em fundo neutro (em cima de um palco, diante de uma parede), ora no cenário mesmo das cenas - e por vezes com os próprios personagens da trama imóveis ao fundo, aguardando a deixa para entrar em ação. Esses interlúdios musicais interrompem repetidas vezes a narrativa, enfraquecendo o drama e chamando a atenção para nada menos do que eles próprios. Em conformidade com o teatro épico de Brecht, que buscava o distanciamento do público em relação ao drama como forma de dissolver o ilusionismo da encenação e provocar a reflexão crítica, esses interlúdios quebram a diegese e devolvem momentaneamente 
o espectador à realidade extra-fílmica. Tal vontade de distanciamento está presente em vários outros aspectos do filme - como nos monólogos em que Galileu (Topol) encara a câmera -, mas é na recorrência do coro que ela se faz mais perceptível.

É interessante ressaltar que, diferentemente do que vimos em Zabriskie Point, Sangue ruim e Paranoid Park, as imagens dos interlúdios, dos números musicais de A vida de Galileu trazem pouco ou nenhum movimento digno da alcunha de dança. Os rapazes do trio encaram uma câmera que está, na maioria das vezes, estática como eles. Assim, por mais que Carroll tenha se precavido contra a eventualidade de uma imagem imóvel, dizendo se tratar apenas de uma opção estilística e não de uma limitação do meio fílmico (CARROLL, 2001, p. 52), seu "conceito expandido de moving-picture dance" fica-nos mais distante. Cabe lembrar que também Epstein, ao discorrer sobre a fotogenia, se precaveu contra a ausência de movimento através de uma ampliação da própria noção de movimento, tomando-o como uma transformação no tempo que não necessariamente implica deslocamento no espaço (XAVIER, 1978, p. 99). Sem a dimensão do deslocamento, contudo, a identificação de um "movimento interessante por si próprio", como quer Carroll, ou de uma "mobilidade fotogênica", como coloca Epstein (EPSTEIN, 1974, p. 139), parece agora inadequada, um pouco fora de lugar. Sem ignorar essas considerações tecidas por Epstein e Carroll com relação à ausência de movimento, questionamos se suas terminologias e preocupações não relegam a imobilidade a um desconfortável segundo plano. Por isso, acreditamos ser oportuno o momento para, afinal, nos despedirmos da analogia da dança que nos norteou até aqui. Busquemos em outras paragens recursos para continuar nossa reflexão sobre a relação entre imagem e suspensão narrativa no cinema.

\section{Na ausência do movimento}

Ao desviarmos o foco da questão do movimento - não por a considerarmos esgotada, mas pela necessidade de propor uma outra forma de abordarmos a ideia de suspensão narrativa -, nos deparamos, em primeiro lugar, com seu oposto: a imagem estática.

Roland Barthes inicia A câmara clara: nota sobre a fotografia (1980) revelando seu espanto diante de uma foto de Jerônimo, o último irmão de Napoleão: "Vejo os olhos que viram o Imperador" (BARTHES, 1984, p. 11). Tal espanto é o que motiva a investigação à qual se dedica o livro, uma busca passional (mais do que técnica ou teórica) por aquilo que faz a essência da imagem fotográfica. No decorrer dessa 
investigação, Barthes identifica dois aspectos da imagem fotográfica que estabelecem entre si uma relação semelhante àquela que vimos entre a narrativa convencional e a atração. Segundo ele, certas imagens apresentam alguma coisa (na maioria das vezes um mero detalhe) que escapa a seu referente e à interpretação que fazemos delas, algo que abre o campo de possibilidades da imagem, que inevitavelmente apela ao olhar do espectador sem que este seja capaz de decifrá-lo plenamente. Àquilo que é da ordem do referente e que se oferece à nossa interpretação, Barthes dá o nome de studium (que remete a "estudo", no sentido de uma aplicação prolongada "mas sem acuidade particular"), enquanto o detalhe fulgurante, o "elemento que vem quebrar (ou escandir) o studium", é nomeado punctum (aquilo que trespassa, "picada", "ferida”). O studium mobiliza um “interesse vago, uniforme, irresponsável”, "que jamais é meu gozo ou minha dor” (BARTHES, 1984, p. 45-49), enquanto o punctum é pura presença e dispensa qualquer análise da imagem, "é o que acrescento à foto e que todavia já está nela” (BARTHES, 1984, p. 85), "como se a imagem lançasse o desejo para além daquilo que ela dá a ver” (BARTHES, 1984, p. 89). Assim, o punctum é, em grande medida, indiferente ao referente da fotografia, ao contexto que a gerou e aos significados que ela promove, mas sem ser indiferente àquele que a olha; ele pode ser uma gola de camisa ou uma rua de terra batida, e ele pode ser indefinível ou indescritível, como a expressão de Bob Wilson ao lado de Phil Glass no retrato de Mapplethorpe:

Bob Wilson me retém, mas não chego a dizer por quê, quer dizer, onde: será o olhar, a pele, a posição das mãos, os sapatos de tênis? O efeito é seguro, mas não é situável, não encontra seu signo, seu nome; é certeiro e no entanto aterrissa em uma zona vaga de mim mesmo; é agudo e sufocado, grita em silêncio. Curiosa contradição: é um raio que flutua (BARTHES, 1984, p. 83).

De certa forma, podemos pensar o studium como aquilo que a fotografia direta e intencionalmente dá a ver e a interpretar, tal qual a imagem cinematográfica que se limitaria a tracionar a narrativa do filme sem extrapolá-la. O punctum, por sua vez, seria como a imagem cinematográfica que se emancipa da narrativa do filme colocando-a em suspensão, ainda que apenas por um instante. Poderíamos, pois, tratar o punctum como um conceito que, de um ponto de partida distinto, percorre caminhos semelhantes àqueles percorridos pela fotogenia e pelo "conceito estendido de moving-picture dance". Mas Barthes, interessado pela fotografia, hesita ao falar da imagem cinematográfica, uma vez que ela, na "voracidade contínua" de seu desfilar perante a lâmpada do projetor, não daria tempo ao processamento do punctum; ele 
prefere o fotograma ao filme (BARTHES, 1984, p. 85-86).

Refletindo especificamente sobre o cinema, Laura Mulvey renova essa preferência pelo fotograma. Em Death $24 x$ a second (2006), ela enxerga nas práticas de pausa, retardamento e repetição do filme - práticas cinéfilas favorecidas por novas tecnologias e hábitos de consumo - meios de acessar a natureza e descobrir detalhes latentes da imagem cinematográfica:

Quando o consumo de filmes é desatrelado de uma visualização absorta absolutamente isolada (no escuro, a 24 quadros por segundo, em ordem narrativa e sem interferências exteriores), a coesão narrativa passa a ser pressionada por discursos externos, pelo contexto, por anedotas, pela história da produção. Mas a espectatorialidade digital também afeta a estrutura interna da narrativa: sequências podem ser facilmente puladas ou repetidas, revertendo hierarquias de privilégios e oferecendo relações inesperadas que desarticulam a cadeia de sentido investida em causas e efeitos. (...) Assim, alguns detalhes ou momentos até então não percebidos podem se tornar ao menos tão significantes quanto a cadeia de sentido investida em causas e efeitos (MULVEY, 2006, p. 27-28).

Mulvey se interessa diretamente pela questão da suspensão narrativa ("narrative halt"), associando-a a "momentos de espetáculo" que não se resumem a movimentos dançantes ou fotogênicos que perturbam profundamente a estrutura narrativa, mas que podem ser suscitados por imagens icônicas e presenças emblemáticas. Para ela, a suspensão narrativa alude sempre à dimensão do registro, ao momento da filmagem com seus sets, estrelas e figurantes, isto é, à "imobilidade do singular frame de celuloide” (MULVEY, 2006, p. 7): nesses momentos, “o fascínio pelo tempo fossilizado supera o fascínio pela progressão narrativa” (MULVEY, 2006, p. 31). Dessa forma, por exemplo, a aparição da estrela já seria operadora de suspensão narrativa, confrontando o tempo do registro ao tempo da ficção (e, também, a performance do ator à sua mera presença), como exemplifica o casal Joyce interpretado por Ingrid Bergman e George Sanders em Journey to Italy (Viagem à Itália, Roberto Rossellini, 1953): "Quando Katherine Joyce escova seu cabelo, vemos Ingrid Bergman escovando o cabelo; quando Alex Joyce fuma um cigarro, vemos George Sanders fumando" (MULVEY, 2006, p. 185). De fato, argumenta Mulvey, a condição de estrela depende de uma performance profundamente capaz de equilibrar a energia de um movimento que atrai o olhar do espectador a uma "imobilidade intensamente controlada e uma habilidade de posar para a câmera” (MULVEY, 2006, p. 162).

Assim, do ínfimo detalhe que captura a atenção de Barthes à acachapante aparição da estrela analisada por Mulvey, uma vasta gama de imagens, em movi- 
mento ou não, se revelam para nós como capazes de refrear a narrativa ficcional que tão frequentemente domina - por ser naturalmente fluida, familiar, confortável - a relação do espectador com o filme. Dentre essas imagens capazes de, a nosso ver, suspender a narrativa, poderemos então encontrar gestos, enquadramentos e movimentos de câmera, paisagens, cortes, sons, rostos, cartelas, objetos, desfoques, enfim, uma infinidade de referentes e de procedimentos que, com intensidades variáveis em cada contexto, tornam a imagem particularmente interessante. Se isso parece indicar, uma vez mais, que qualquer imagem pode eventualmente ser “interessante por si própria”, é também porque o espectador tem um papel decisivo: em última análise, é ele quem vai assimilar, ou não, a suspensão narrativa. A narrativa só é convencional se ele reconhece suas convenções e só é suspensa quando ele ultrapassa a arbitrariedade dessas convenções ou testemunha sua fragilidade; a narrativa e sua suspensão não existem apenas no filme, elas precisam também de um olhar que as reconheça como tais. Eis que, se o espectador não conhece Ingrid Bergman e George Sanders, o casal Joyce corre o risco de se tornar, ao menos do ponto de vista da imagem, particularmente desinteressante.

\section{Narrativas elásticas}

A via trabalhada por Barthes e Mulvey a partir da imagem estática nos oferece, portanto, uma alternativa à abordagem que privilegia o movimento, complementando a definição de suspensão narrativa que pretendíamos esboçar. Ela incorpora espontaneamente o espectador, atribuindo-lhe um papel crucial e que nunca é demais reafirmar, e parece expor com mais clareza o que até então poderíamos apenas intuir: a suspensão narrativa não necessariamente implica uma interrupção da narrativa. É um procedimento mais propriamente elástico que fragmentário: a imagem que aqui consideramos interessante (que opera a suspensão) é como uma força que tensiona a linha narrativa fazendo-a se curvar em ângulos mais ou menos agudos, mas que, na maioria das vezes, não a arrebenta. Arrebentar a linha seria romper não apenas com a narrativa, mas com a unidade, a inteireza do filme - como fazem os habituais créditos finais que, letra branca sobre fundo preto, se revelam suspensões narrativas por excelência, ainda que nada espetaculares 5 . O espectador minimamente atento dificilmente pode se impedir de buscar relações entre as imagens e a história contada, ele dificilmente se esquiva de tentar fazer sentido daquilo que vê, mantendo íntegra

\footnotetext{
${ }_{5}^{5}$ Convém lembrar, no entanto, que certos créditos buscam prolongar o apelo narrativo e/ou espetacular do filme recorrendo a cenas adicionais e animações além de, o que é mais sutil e mais frequente, se valer da atmosfera criada pela trilha musical que os acompanha.
} 
a linha mesmo lá onde ela parece mais quebradiça.

Um exemplo de elasticidade narrativa pode ser encontrado em Punch drunk love (Embriagado de amor, Paul Thomas Anderson, 2002), nos momentos em que a tela é subitamente preenchida por uma série de pinturas digitais do artista Jeremy Blake. As tarjas e borrões animados em lentas fusões de cores não condizem em nada com as desventuras tragicômicas do tímido Barry Egan (Adam Sandler), que encontra um estranho instrumento musical no meio da rua, se envolve com mafiosos responsáveis por um serviço de tele-sexo e coleciona centenas de embalagens de gelatina para concorrer a milhas aéreas.

Já em Sanxia Haoren (Em busca da vida, Jia Zhangke, 2006), a linha narrativa se revela elástica por meio de imagens que flertam com o surrealismo: um disco voador que atravessa o horizonte, um edifício que decola como um foguete espacial e um equilibrista que caminha por uma corda bamba em meio a ruínas (último plano do filme). Essas imagens absurdas surgem à revelia do realismo da trama, que se divide entre as histórias de um mineiro (Han Sanming) à procura da esposa e da filha e de uma enfermeira (Zhao Tao) em busca do marido que a abandonou, ambos vagando por uma cidade parcialmente destruída para dar lugar a uma represa.

Em um último exemplo, a linha narrativa de Cleópatra (Júlio Bressane, 2007) faz da exibição de sua elasticidade a própria singularidade do filme. Há uma profusão de imagens que se desinteressam da história da mítica rainha egípcia que lhe deveria servir de garantia. Em um momento, vemos apenas as dobras da túnica de Júlio César (Miguel Falabella) por um minuto inteiro, período ao final do qual o personagem retoma o discurso para seus conselheiros como se não tivesse havido interrupção alguma; noutro momento, enquanto um profeta descreve o futuro da rainha (Alessandra Negrini), a câmera orbita em plano detalhe um sexo feminino; mais adiante, uma série de retratos filmados de Cleópatra se prolonga por quase dois minutos, como que construindo um inventário de suas expressões faciais. A excentricidade dessas e de outras tantas imagens comprometem as motivações e conexões da trama a ponto de deixá-la, por assim dizer, quase incompreensível.

Esses exemplos nos colocam novamente diante de imagens que desafiam a interpretação, imagens às quais não está atribuído nenhum sentido evidente e que, ainda assim, forçam o espectador a buscar algum sentido. Quando porventura encontrado, esse sentido não é nem "comunicação" nem "significação"; essas imagens não nos informam nada de objetivo pertinente à trama e tampouco remetem a um nível simbólico que nos permita interpretá-las com segurança. O sentido encontrado é, antes, o que Barthes considera uma "passagem da linguagem à significância" 
(BARTHES, 1990, p. 58), um “terceiro sentido” ou "sentido obtuso" “que é 'demais', que se apresenta como um suplemento que minha intelecção não consegue absorver bem” (BARTHES, 1990, p. 47), “que não se pode descrever” (BARTHES, 1990, p. 58): “(...) graças ao que, na imagem, é puramente imagem (e que, na verdade, é muito pouca coisa), podemos passar sem a palavra e continuamos a nos entender" (BARTHES, 1990, p. 55).

Elegendo como objeto de análise o filme Ivan Grozniy (Ivan, o terrível, Sergei Eisenstein, 1944), Barthes sugere que esse "terceiro sentido" seria "o ato fundador do próprio fílmico", explicando que o fílmico seria para o filme o que o romanesco é para o romance: "posso escrever romanescamente, sem nunca escrever um romance” (BARTHES, 1990, p. 58). O “terceiro sentido” seria então uma maneira de dizer a essência da imagem cinematográfica, em uma formulação que, a nosso ver, antecipa o conceito de punctum, central em sua investigação sobre a imagem fotográfica ${ }^{6}$. Assim como o punctum, o "terceiro sentido" deliberadamente descarta o movimento: para Barthes, o fílmico “não pode ser apreendido no filme 'em situação', 'em movimento', 'ao natural', mas apenas, repito, nesse artefato maior que é o fotograma" (BARTHES, 1990, p. 58). Com essa afirmação, Barthes defende que a essência do cinema está encerrada em uma imobilidade, hipótese que, além de contra-intuitiva, não nos parece sustentável. É Cristian Borges quem, retomando o Eisenstein citado pelo próprio Barthes, desfaz o equívoco. Ele desloca o "fílmico" do fotograma para um movimento inalienável que se situa não na passagem de uma imagem a outra (de um fotograma ou um plano a outro), mas no interior mesmo de cada imagem:

acreditamos que a imagem cinematográfica só existe e pode ser considerada enquanto tal em movimento, e é também nesse sentido que ela se encontra além do fotograma e aquém do plano. Não à toa, Serguei Eisenstein, ao tratar das novas possibilidades da montagem audiovisual, afirmou que: "o centro de gravidade fundamental (...) transfere-se para dentro do fragmento, dos elementos incluídos na própria imagem. E o centro de gravidade já não é o elemento 'entre os planos' - o choque -, mas o elemento 'dentro do plano' - a ênfase no interior do fragmento (apud Barthes, 1990, p. 59). Trata-se, assim, de algo que se passa dentro das imagens e não no choque entre elas logo, algo que seria, antes, da ordem do evento. (BORGES, 2011, p. 159).

Feita essa ressalva, cabe observar que, ao apontar para algo que seria a essência do cinema (algo ao qual restituímos, com Borges, a dimensão do movimento que

"Publicado originalmente em 1970 na Cahiers du cinéma, o artigo "O terceiro sentido" antecede em uma década o livro A câmara clara (1980), no qual Barthes conceitua o punctum fotográfico. 
Barthes prefere ignorar), e por sua assumida indescritibilidade, o "terceiro sentido" seria uma espécie de retorno à fotogenia. Entretanto, diferentemente dos contornos incomodamente borrados do conceito de fotogenia ${ }^{7}$, a formulação do "terceiro sentido" aponta mais nitidamente para uma importante divisão entre imagem e sentido. Ela indica que não competiria mesmo à imagem cinematográfica, sozinha, fazer pleno sentido. A “comunicação" e a "significação", chamados por Barthes de sentidos óbvios, não são inerentes à esfera da imagem cinematográfica, mas sim à narrativa - de certo modo, é a narrativa que precisa ser lógica e interpretável, não a imagem. A imagem é "muito pouca coisa", ela é apenas um elemento material que precede - e que excede - a narrativa. Tal é a perspectiva adotada por Kristin Thompson, que se apropria da reflexão de Barthes rebatizando o "terceiro sentido" como "excesso" em seu artigo "The concept of cinematic excess" $(1977)^{8}$.

\section{A imagem como matéria}

Thompson esclarece que todo filme tem uma existência material, sendo que “o processo de 'disposição’ dos materiais em estruturas não elimina sua materialidade original" (THOMPSON, 1977, p. 56). As imagens e sons são, pois, os elementos físicos que, ao serem formalmente organizados, sustentam a narrativa - mas essa mesma narrativa não esgota todas as imagens e sons que a sustentam. Para ficarmos apenas com o primeiro exemplo de Ivan, o terrível que Barthes nos oferece, cena na qual dois cortesãos derramam moedas de ouro sobre a cabeça do czar:

(...) é uma certa espessura na maquilagem dos cortesãos, por vezes pesada, marcada, por vezes lisa, distinta; é o nariz 'bobo' de um deles, é o fino arco das sobrancelhas de outro, sua louridão sem brilho, sua tez branca e sem vida, o penteado impecável que denota a peruca, a amálgama de base ressecada e pó-de-arroz. (...) dizer que esses traços remetem a um 'ar' significativo dos cortesãos, aqui distante, lá aplicado ('Cumprem apenas seu papel de cortesãos'), não me satisfaz plenamente: algo, nesses dois rostos, vai além da psicologia da trama, da função e, para resumir, do sentido, sem, no entanto, limitar-se à teimosia que faz com que o corpo humano esteja lá (BARTHES, 1990, p. 46).

\footnotetext{
${ }_{7}$ Para Ismail Xavier, a fotogenia é uma ideia palatável quando se ponderava sobre "o que ela não designava e onde ela não estava" mas que deixava as coisas "obscuras quando se tratava de superar e determinar, afinal, o que ela, como conceito, recobria” (XAVIER, 1978, p. 93-94).

${ }^{8}$ Thompson reemprega o termo "excesso" utilizado por Stephen Heath em seu artigo "Film and system: Terms of analysis" (1975), preferindo-o ao termo utilizado por Barthes. No entanto, são as ideias de Barthes que ela retoma, criticando duramente a análise oferecida por Heath (THOMPSON, 1977, p. 55).
} 
Dessa forma, mesmo nos mais clássicos filmes de Hollywood, filmes que investiriam em uma máxima “integração narrativa”, isto é, que insistiriam em trazer motivações e causalidades para todas as imagens que apresentam (que evitariam a todo custo, portanto, as suspensões narrativas), pode haver uma materialidade que se excede, porque "a materialidade da imagem vai além das estruturas narrativas que conferem unidade ao filme" (THOMPSON, 1977, p. 55). Essa materialidade excessiva não diz respeito nem à trama (no caso de Ivan, aos acontecimentos que envolvem o czar e os cortesãos, informados pelas ações, cenários, figurinos etc.), nem à interpretação que ela demanda (ao poder do terrível czar significado pelo derramamento do ouro sobre sua cabeça), e tampouco pode ser tomada exclusivamente como algo que remete ao momento da filmagem (à presença do corpo humano que ali se encontra fossilizado em celuloide, questão sobre a qual se debruça Mulvey).

Seguindo a argumentação de Thompson, quanto mais coincide com a motivação narrativa, mais a materialidade da imagem pode passar desapercebida; seu excesso, contudo, acarreta uma suspensão da trama lógica e causal, pois “o excesso implica uma lacuna ou um atraso na motivação” (THOMPSON, 1977, p. 57). Por fim, reencontramos também em Thompson o espectador ativo na ocorrência de suspensão narrativa: "Presumivelmente, a única maneira de o excesso deixar de afetar o sentido é se o espectador não o percebe; é uma questão de treino e de background" (THOMPSON, 1977, p. 55). O espectador atento, treinado - ou munido das ferramentas de pausa, retardamento e repetição de imagens de que Mulvey nos fala -, é um espectador sensível ao excesso, ou seja, um espectador propenso a ser surpreendido pela arbitrariedade da narrativa deflagrada pela cintilante materialidade da imagem.

\section{Conclusão: abertura à plasticidade}

Neste artigo, buscamos refletir sobre os modos pelos quais a imagem é capaz de operar suspensões na narrativa cinematográfica convencional. Ao invés de elencarmos as características da imagem e os procedimentos estéticos que seriam capazes de criar "suspensão narrativa” - tarefa que seria, desconfiamos, interminável e pouco proveitosa -, preferimos nos esforçar em uma investigação teórica sobre a relação entre a imagem e a narrativa, analisando em particular os momentos em que eles não se correspondem inteiramente, ou seja, os momentos em que a imagem se faz interessante de um modo indiferente à narrativa. Interrompemos agora esta investigação esperando ter revelado, também, algumas vicissitudes da própria narrativa 
cinematográfica relacionadas a sua imagética materialidade.

A nosso ver, a suspensão narrativa demanda, de fato, uma imagem, que podemos eventualmente chamar de interessante por si própria, fotogênica ou excessiva, e que podemos reconhecer até mesmo no fade out e na tela escura que habitualmente acolhem os créditos finais de um filme. A ocorrência dessa suspensão, no entanto, não se deve unicamente à força da imagem, mas também a um potencial intrínseco à narrativa cinematográfica, por mais convencional que ela seja. Trata-se de um potencial elástico que a permite se reconfigurar à guisa das imagens.

Se a imagem opera, revela, escancara a suspensão narrativa, esta, por sua vez, vem escancarar a elasticidade da própria narrativa cinematográfica. Aquilo que Kristin Thompson aponta como uma "arbitrariedade” - “a arbitrariedade subjacente à narrativa é camuflada por suas estruturas de motivação e naturalização" (THOMPSON, 1977, p. 62)-, preferimos reconhecer como "plasticidade", termo que nos parece mais fértil. Acreditamos que esse viés teórico poderá contribuir de forma significativa para a reflexão sobre a narrativa e a suspensão narrativa no cinema em trabalhos por vir. Por ora, digamos assim: a narrativa parece arbitrária porque é elástica.

Por uma definição filosófica do termo proposta por Catherine Malabou, é plástico aquilo que é susceptível tanto a receber forma (como uma argila) quanto a atribuir forma (como se diz das "artes plásticas" ou da "cirurgia plástica”). A elasticidade de que a narrativa nos faz prova, sendo suspensa e ao mesmo tempo resistindo à suspensão, provém de sua plasticidade, porque plástico é, também, aquilo que “é capaz de manter a forma que lhe foi dada e de resistir ao movimento de uma deformação infinita” (MALABOU, 2000, p. 311-312). Não apenas a narrativa informa (organiza formalmente, dá forma) as imagens, emprestando-lhes lógica e sentidos, mas é também modelada e deformada por elas.

Após alinharmos diversas noções que parcialmente se justapõem e oportunamente se complementam - o "conceito estendido de moving-picture dance", a "fotogenia", o "número musical", a "atração", o "punctum", o "terceiro sentido", o "excesso" -, é então com a plasticidade que encerramos este estudo. Esperamos que ele possa, com possibilidades de abordagem mais do que com respostas e com perguntas mais do que com exemplos pontuais, tornar mais palpável a questão da suspensão narrativa no cinema - questão inquieta que, como tantas outras, se debate contra definições. Questão que encontra, de um lado, mais de um século de convenções narrativas e, de outro, imagens que insurgem justamente contra essas convenções, despertando nosso interesse. Questão que podemos apenas, afinal, manter em aberto. 


\section{Referências bibliográficas}

ALTMAN, R. "The American film musical as dual-focus narrative". In. The American film musical. Bloomington-Indianapolis: Indiana University Press, 1987, p. 16-27. . (org.). Genre: The musical. Cambridge: Cambridge University Press, 1981. BARTHES, R. A câmara clara. Rio de Janeiro: Nova Fronteira, 1984.

" "O terceiro sentido". In. O óbvio e o obtuso. Rio de Janeiro: Nova Fronteira, 1990, p. 45-61.

BORDWELL, D. Narration in the fiction film. Madison: University of Wisconsin Press, 1985.

BORGES, C. "Da pose fotográfica à passagem cinematográfica: Fundamentos da imagem fotossensível”. Significação, no 35, 2011, p. 153-167.

"Mais perto do coração selvagem (do cinema)". In. GONÇALVES, O. (org.). Narrativas sensoriais: Ensaios sobre cinema e arte contemporânea. Rio de Janeiro: Circuito, 2014, p. 41-59.

CARROLL, N. "Toward a definition of moving-picture dance". Dance research journal, 33/1, verão de 2001, p. 46-61.

EPSTEIN, J. "Le cinématographe vu de l'Etna". In. Écrits sur le cinéma, tome 1: 1921-1947. Paris: Éditions Seghers, 1974, p. 131-168.

GAUDREAULT, A. Film and attraction: From kinematography to cinema. Chicago/ Springfield: University of Illinois Press, 2011.

; GUNNING, T. "Early cinema as a challenge to film history". In STRAUVEN, W. (org.). The cinema of attractions reloaded. Amsterdã: Amsterdam University Press, 2006, p. 365-380.

; JOST, F. A narrativa cinematográfica. Brasília: Editora UnB, 2009.

GUNNING, T. "The cinema of attraction[s]: Early film, its spectator and the Avant-Garde. In STRAUVEN, W. (org.). The cinema of attractions reloaded. Amsterdã: Amsterdam University Press, 2006, p. 381-388.

HEATH, S. "Film and system: Terms of analysis - part I". Screen, vol. 16, n 1, primavera de 1975 , p. 7-77.

MALABOU, C. "Plasticité surprise". In MALABOU, C. (org.). Plasticité. Paris: Léo Scheer, 2000, p. 310-323.

MULVEY, L. Death 24x a second. Londres: Reaktion Books, 2006.

STRAUVEN, W. "Introduction to an attractive concept". In STRAUVEN, W. (org.). The cinema of attractions reloaded. Amsterdã: Amsterdam University Press, 2006, p. $11-27$.

SUTTON, M. "Patterns of meaning in the musical". In. ALTMAN, R. (org.). Genre: The musical. Cambridge: Cambridge University Press, 1981, p. 190-196. 
THOMPSON, K. “The concept of cinematic excess". Ciné-tracts, $\mathrm{n}^{\circ} 2$, verão de 1977 , p. $54-63$.

XAVIER, I. "Do ritmo à fotogenia”. In. Sétima arte: Um culto moderno. São Paulo: Perspectiva, 1978, p. 79-102.

\section{Referências audiovisuais}

BALLET mécanique (Dudley Murphy e Fernand Léger, 1924)

CLEÓPATRA (Júlio Bressane, 2007)

GALILEO (A vida de Galileu, Joseph Losey, 1975)

IVAN Grozniy (Ivan, o terrivel, Sergei Eisenstein, 1944)

JOURNEY to Italy (Viagem à Itália, Roberto Rossellini, 1953)

MAUVAIS sang (Sangue ruim, Leos Carax, 1986)

PARANOID Park (Gus Van Sant, 2007)

PUNCH drunk love (Embriagado de amor, Paul Thomas Anderson, 2002)

SANXIA Haoren (Em busca da vida, Jia Zhangke, 2006)

ZABRISKIE Point (Michelangelo Antonioni, 1970)

submetido em: 04 fev. 2016 | aprovado em: 15 abr. 2016. 